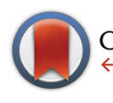

CrossMark $\leftarrow$ click for updates

Cite this: Dalton Trans., 2016, 45 4179

Received 8th September 2015, Accepted 16th October 2015 DOI: $10.1039 / c 5 d t 03510 d$ www.rsc.org/dalton

\title{
Structure and properties of Al-MIL-53-ADP, a breathing MOF based on the aliphatic linker molecule adipic acid $\uparrow$
}

\author{
Helge Reinsch, ${ }^{\star a}$ Renjith S. Pillai, ${ }^{b}$ Renée Siegel, ${ }^{c}$ Jürgen Senker, ${ }^{c}$ Alexandra Lieb, ${ }^{d}$ \\ Guillaume Maurin ${ }^{\mathrm{b}}$ and Norbert Stock ${ }^{* \mathrm{e}}$
}

\begin{abstract}
The new aluminium based metal-organic framework $\left[\mathrm{Al}(\mathrm{OH})\left(\mathrm{O}_{2} \mathrm{C}-\mathrm{C}_{4} \mathrm{H}_{8}-\mathrm{CO}_{2}\right)\right] \cdot \mathrm{H}_{2} \mathrm{O}$ denoted as AlMIL-53-ADP-Ip (lp stands for large pore) was synthesised under solvothermal conditions. This solid is an analogue of the archetypical aluminium terephthalate Al-MIL-53 based on the aliphatic single-chain linker molecule adipic acid ( $\mathrm{H}_{2} \mathrm{ADP}$, hexanedioic acid). In contrast to its aromatic counterparts, Al-MIL-53ADP exhibits a structural breathing behaviour solely upon dehydration/rehydration. The crystal structure of the anhydrous compound denoted as Al-MIL-53-ADP-np (np stands for narrow pore) was determined by a combination of forcefield-based computations and Rietveld refinement of the powder X-ray diffraction data while the structure of the hydrated form Al-MIL-53-ADP-lp was derived computationally by a combination of force field based methods and Density Functional Theory calculations. Both structures were further supported by ${ }^{1} \mathrm{H},{ }^{13} \mathrm{C}$ and ${ }^{27} \mathrm{Al}$ high-resolution NMR MAS $1 \mathrm{D}$ data coupled again with simulations. Al-MIL-53-ADP was further characterised by means of vibrational spectroscopy, elemental analysis, thermogravimetry and water vapour sorption.
\end{abstract}

\section{Introduction}

Metal-organic frameworks (MOFs) are hybrid porous materials that have been widely studied due to their promises in several fields of applications like gas storage, ${ }^{1}$ separation of mixtures of gases ${ }^{2}$ or liquids, ${ }^{3}$ catalysis ${ }^{4}$ or sensing. ${ }^{5}$ Among the variety of reported MOFs a sub-group of materials exhibits a rare structural phenomenon denoted as "breathing". ${ }^{6}$ This corresponds to a fully reversible transition between different framework conformations triggered by an external stimulus which leads to large changes of the cell parameters. Such a stimulus is typically given by temperature, external pressure or the presence of certain guest molecules inside the pores of the framework. ${ }^{7}$ A particularly interesting series of compounds that

\footnotetext{
${ }^{a}$ Department of Chemistry, University of Oslo, P.O. Box 1033 Blindern, 0315 Oslo, Norway. E-mail: helge.reinsch@smn.uio.no

${ }^{b}$ Institut Charles Gerhard Montpellier, UMR-5253 Université Montpellier CNRS ENSCM, Place E. Bataillon 34095, Montpellier cedex 05, France.

E-mail: guillaume.maurin@univ-montp2.fr

${ }^{c}$ Inorganic Chemistry III, University Bayreuth, Universitätsstaße. 30, 95447 Bayreuth, Germany

${ }^{d}$ Institute of Chemistry, Universitätsplatz 2, 39106 Magdeburg, Germany

${ }^{e}$ Institute of Inorganic Chemistry, Christian-Albrechts-Universität Kiel, Max-Eyth-Straße 2, 24118 Kiel, Germany.E-mail: stock@ac.uni-kiel.de $\dagger$ Electronic supplementary information (ESI) available: Additional XRPD-data, simulated PSD, crystallographic information files, simulated NMR data. See DOI: $10.1039 / \mathrm{c} 5 \mathrm{dt} 03510 \mathrm{~d}$
}

shows this structural flexibility is the MIL-53-series (MIL stands for Materials of Institute Lavoisier). These solids are built up by the interconnection of infinite chains of trans corner sharing $\mathrm{MO}_{6}$ polyhedra (where $\mathrm{M}$ designates a trivalent metal cation) and linear dicarboxylate ions, leading to rhombic channels. The pore dimensions are changed during such a breathing phenomenon and this is mostly affected by a rotation around the $\mathrm{O}-\mathrm{O}$-axis of the carboxylate moieties, the so-called knee-cap mechanism. ${ }^{8}$ Until now several metal ions were proven to form this framework structure like $\mathrm{Sc}^{3+},{ }^{9} \mathrm{~V}^{3+}, 10$ $\mathrm{Cr}^{3+},{ }^{11} \mathrm{Fe}^{3+},{ }^{12} \mathrm{Al}^{3+},{ }^{13} \mathrm{Ga}^{3+}$ (ref. 14 ) and $\mathrm{In}^{3+} .{ }^{15}$ Their structures and properties have been studied under a wide variety of conditions and especially the nature of the linker molecule was shown to have a profound impact on the breathing. Employing functionalised terephthalates for the synthesis of MOFs based on, for example, $\mathrm{Fe}^{3+},{ }^{16} \mathrm{Al}^{3+}$ (ref. 17) or $\mathrm{V}^{3+}$ (ref. 18) strongly affects the sorption properties and micropore volumes. Moreover the different framework conformations are massively affected by the size of the linker molecules. Extending the linker molecule by employing 2,6-naphthalenedicarboxylic acid or 4,4'-biphenyldicarboxylic acid leads to frameworks which do not show any breathing behaviour, as it was demonstrated for example for $\mathrm{Al}^{-19,20}$ and $\mathrm{V}$-MOFs. ${ }^{21}$ In a similar manner the use of shorter linker molecules such as fumaric acid was proven to drastically decrease the breathing in an AlMOF with MIL-53 topology to $3-4 \%$ of the cell volume. ${ }^{22}$ Very few studies of MOFs related to MIL-53 deal with aliphatic 
linker molecules. Employing trans-1,4-cyclohexanedicarboxylic acid $\left(\mathrm{H}_{2} \mathrm{CDC}\right)$ and $\mathrm{In}^{3+}$ or $\mathrm{Cr}^{3+}$, such materials could be obtained. ${ }^{23,24}$ However, these compounds were not reported to show any kind of breathing. More recently it was also possible to synthesise the $\mathrm{CDC}^{2-}$ based aluminium MOF with MIL-53 structure, denoted as CAU-13 (where CAU stands for ChristianAlbrechts-Universität). ${ }^{25}$ Remarkably it was shown that the knee-cap mechanism is not dominant in the breathing of this framework upon adsorption. Instead, the dimension of the channels is mainly altered due to conformational changes of the cyclohexane ring. ${ }^{26}$ When water or no guest molecules are present in the pores, half of the linker molecules adopt $a, a$ conformation and the other half the e,e-conformation. Upon adsorption of xylene, all linker molecules adopt the $e, e$-conformation and thus the channel diameter is increased from 3.5 to 5 A. The same effect was observed for $\mathrm{Ga}^{3+}$ based CAU-13. ${ }^{27}$

Herein, we report the aluminium based metal-organic framework $\left[\mathrm{Al}(\mathrm{OH})\left(\mathrm{O}_{2} \mathrm{C}-\mathrm{C}_{4} \mathrm{H}_{8}-\mathrm{CO}_{2}\right)\right]$ or Al-MIL-53-ADP (ADP stands for adipate) and its breathing behaviour, which is the first example of a MIL-53 framework based on a single-chain saturated aliphatic linker molecule.

\section{Experimental}

\section{Materials}

All chemicals are commercially available and were used without further purification.

\section{Methods}

The synthesis was carried out in Pyrex glass bottles with screw cap and a volume of $100 \mathrm{~mL}$. Powder X-ray diffraction (PXRD) data was collected on a STOE Stadi P diffractometer equipped with a linear position sensitive detector (PSD) using monochromated $\mathrm{CuK}_{\alpha 1}$ radiation in transmission geometry. All processing of the crystallographic data was done with TOPAS. $^{28}$ PXRD data depending on humidity was collected on a Bruker PANalytical Empyrean diffractometer ( $\mathrm{CuK}_{\alpha}$-radiation). Elemental analysis was measured with an Eurovektor EuroEA Elemental Analyzer. IR-spectra were measured on a Bruker ALPHA-FT-IR A220/D-01 spectrometer equipped with an ATRunit. The thermogravimetric analyses were recorded using a TA instruments Q500 with a heating rate of $10 \mathrm{~K} \mathrm{~min}^{-1}$ under oxygen flow. Sorption experiments were performed using a BEL JAPAN INC. Belsorp max.

All solid-state NMR experiments were acquired on Bruker Avance-III HD spectrometers operating at a $B_{0}$ field of $14.1 \mathrm{~T}$ $\left({ }^{1} \mathrm{H}\right.$ and $\left.{ }^{27} \mathrm{Al}\right)$ and $9.4 \mathrm{~T}\left({ }^{13} \mathrm{C}\right) .{ }^{1} \mathrm{H}(600.15 \mathrm{MHz})$ high-resolution spectra were acquired after a $90^{\circ}$ pulse of $1.4 \mu$ s with a spinning speed of $62.5 \mathrm{kHz}$ using a commercial $1.3 \mathrm{~mm}$ MAS double resonance probe (Bruker). ${ }^{13} \mathrm{C}(100.6 \mathrm{MHz})$ MAS spectra were obtained with a ramped cross-polarization (CP) experiment where the nutation frequency $\nu_{\text {nut }}$ on the proton channel was varied linearly by $50 \%$. The samples were spun at $12.5 \mathrm{kHz}$ in a $4 \mathrm{~mm}$ MAS double resonance probe (Bruker). The corresponding $\nu_{\text {nut }}$ on the ${ }^{13} \mathrm{C}$ channel and the contact time were adjusted to $70 \mathrm{kHz}$ and $3.0 \mathrm{~ms}$, respectively. Proton broadband decoupling with spinal-64 was applied during acquisition. Both the ${ }^{1} \mathrm{H}$ and ${ }^{13} \mathrm{C}$ spectra are referenced with respect to TMS (tetramethylsilane) using the secondary standard adamantane. Finally, the ${ }^{27} \mathrm{Al}(156.4 \mathrm{MHz})$ 1D MAS experiments were acquired using a rotor-synchronized spinecho with central transition selective $90^{\circ}$ and $180^{\circ}$ pulses of 12.5 and $25 \mu$ s (to remove the resonances from the satellite transitions) at a spinning speed of $20 \mathrm{kHz}$ (3.2 mm MAS triple resonance probe, Bruker). The reference was set using a solution of $\mathrm{AlCl}_{3}$ adjusted to a $\mathrm{pH}$ of one with hydrochloric acid. The ${ }^{27} \mathrm{Al}$ spectra were fitted using the simulation package SOLA included in Bruker's Topsin3.2 software.

The force field based-geometry optimizations were conducted using the Forcite software available in the Materials Studio package and the generic Universal Force Field LennardJones parameters for all atoms of the MOF framework. ${ }^{29}$

The DFT geometry optimizations were performed with the QUICKSTEP module, available as part of the CP2K code using the PBE functional and the triple zeta basis set (TZVP-MOLOPT) for all atoms, except for the Al centres, where double zeta functions (DZVP-MOLOPT) were considered. Semi-empirical dispersion corrections as implemented in the DFT-D3 method were taken into account. ${ }^{30}$ These calculations considered simulation boxes consisting of $(1 \times 2 \times 2)$ and $(2 \times 2 \times 2)$ unit cells for the anhydrous and hydrated phases respectively. The first-principles calculations of the NMR parameters were performed from the structural models for both the large and the narrow pore forms with CASTEP $^{31,32}$ using the PBE functional ${ }^{33}$ and ultra-soft pseudo-potentials generated 'on the fly'. ${ }^{34}$ The wave functions were expanded on a plane wave basis set with a kinetic energy cut-off of $610 \mathrm{eV}$. The projector augmented waves (PAW) ${ }^{35}$ and gauge included projector augmented waves (GIPAW) ${ }^{36}$ algorithms for the EFGs and NMR chemical shifts, respectively.

\section{Synthesis}

Al-MIL-53-ADP was synthesised from a mixture of $10.88 \mathrm{~g}$ (16.33 mmol) $\mathrm{Al}_{2}\left(\mathrm{SO}_{4}\right)_{3} \cdot 18 \mathrm{H}_{2} \mathrm{O}, 2.4 \mathrm{~g}(16.33 \mathrm{mmol})$ adipic acid, $21 \mathrm{~mL} \mathrm{H}_{2} \mathrm{O}$ and $9 \mathrm{~mL}$ dimethylformamide. The slurry was thoroughly mixed and heated to $130{ }^{\circ} \mathrm{C}$ for $12 \mathrm{~h}$. After cooling down to room temperature the raw product was filtered off and thoroughly ground to obtain a fine powder. This powder was redispersed in $50 \mathrm{~mL} \mathrm{H}_{2} \mathrm{O}$ by stirring at room temperature for $1 \mathrm{~h}$ and filtrated again. Despite this treatment the product still contains minor impurities of sulphur, probably originating from the sulphate ions in the starting mixture. Thus the elemental analysis detected $32.9 \% \mathrm{C}, 5.1 \% \mathrm{H}$ and $1.0 \% \mathrm{~S}$. The values calculated for the fully hydrated form $\left[\mathrm{Al}(\mathrm{OH})\left(\mathrm{O}_{2} \mathrm{C}-\right.\right.$ $\left.\left.\mathrm{C}_{4} \mathrm{H}_{8}-\mathrm{CO}_{2}\right)\right] \cdot \mathrm{H}_{2} \mathrm{O}$ are slightly deviating and amount to $34.9 \% \mathrm{C}$ and $5.3 \% \mathrm{H}$. Several attempts for complete removal of the impurities by boiling in water or dimethylformamide with or without stirring at various temperatures did not lower the sulphur content any further. For the PXRD measurements the samples were prepared directly after filtration from aqueous dispersion (Al-MIL-53-ADP-lp) or after heating the MOF at $180^{\circ} \mathrm{C}$ in air for three hours (Al-ML-53-ADP-np). 


\section{Results and discussion}

\section{Structure determination}

The PXRD pattern of the anhydrous Al-MIL-53-ADP (Fig. 1) exhibits much higher crystallinity than the pattern of the hydrated compound (Fig. S1 H $_{\text {) }}$ and therefore the structure determination started with this framework conformer. The indexed unit cell shows a monoclinic symmetry $(a=15.828(2) \AA$, $\left.b=7.947(2) \AA, c=6.611(2) \AA, \beta=93.78(2)^{\circ}\right)$ with extinction conditions suitable for space group $P 2_{1}$. A first model for successful refinement was deduced starting from the structure of the iron pyromellitate MIL-82 ${ }^{37}$ using supergroup/subgroup relationships. This MIL-53-type framework structure was converted from $C 2 / c$ into the respective subgroups $P 2_{1} / m$ and $P 2_{1}$ using Powdercell. ${ }^{38}$ The so-obtained structure with lower symmetry was adapted to the indexed cell parameters and the pyromellitate ions were replaced by adipate ions. This structural model was geometry-optimised at the force field level and subsequently refined by Rietveld methods. The final plot is shown in Fig. 1 and relevant parameters are summarised in Table 1.

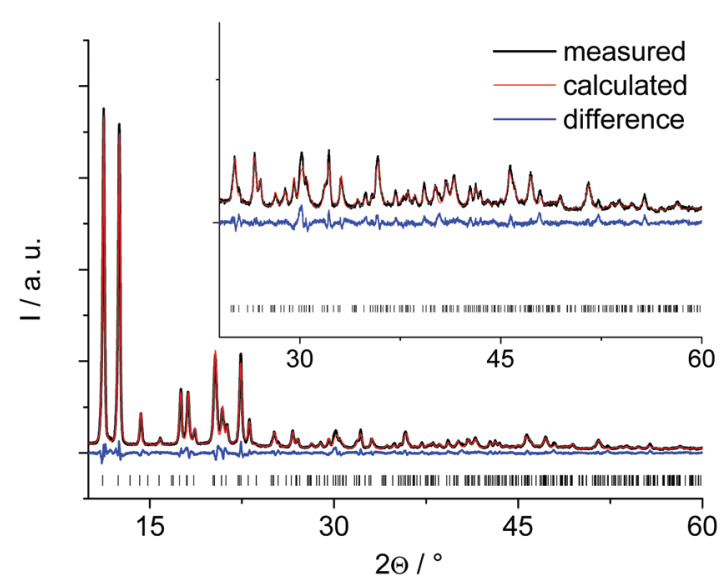

Fig. 1 The Rietveld plot for the anhydrous Al-MIL-53-ADP-np. The black line is the experimental data, the red line is the fit and the blue line the difference curve. Vertical bars mark the Bragg reflection positions.

Table 1 Relevant parameters for the different forms of Al-MIL-53-ADP

\begin{tabular}{lll}
\hline Ideal formula & {$\left[\mathrm{Al}(\mathrm{OH})\left(\mathrm{O}_{2} \mathrm{C}-\mathrm{C}_{4} \mathrm{H}_{8}-\mathrm{CO}_{2}\right)\right]$} & $\begin{array}{l}{\left[\mathrm{Al}(\mathrm{OH})\left(\mathrm{O}_{2} \mathrm{C}-\mathrm{C}_{4} \mathrm{H}_{8}-\mathrm{CO}_{2}\right)\right]} \\
\mathrm{H}_{2} \mathrm{O}\end{array}$ \\
Crystal system & Monoclinic & Triclinic \\
Space group & $P 2_{1}$ & $P 1$ \\
$a / \AA$ & $15.8741(8)$ & 6.6289 \\
$b / \AA$ & $7.9646(3)$ & 8.6458 \\
$c / \AA$ & $6.6187(3)$ & 9.0811 \\
$\alpha /{ }^{\circ}$ & 90 & 62.429 \\
$\beta /{ }^{\circ}$ & $93.669(5)$ & 87.743 \\
$\gamma /{ }^{\circ}$ & 90 & 88.372 \\
$V / \AA^{3}$ & $835.1(3)$ & 461.0 \\
Method & Rietveld refinement & DFT calculation \\
$R_{\mathrm{wp}} / \%$ & 8.1 & - \\
$R_{\mathrm{Bragg}} / \%$ & 1.5 & - \\
GoF & 2.2 & -
\end{tabular}

The crystallographic information file and the most relevant bond distances are given in the ESI. $\dagger$

For the hydrated form Al-MIL-53-ADP-lp we started with the indexed triclinic cell parameters $(a=6.623(2) \AA, b=8.624(2) \AA$, $\left.c=9.058(2) \AA, \alpha=117.38(2)^{\circ}, \beta=92.54(1)^{\circ}, \gamma=88.27(2)^{\circ}\right)$ which were obtained after a structure-less cell parameter refinement.

These lattice parameters are similar to the ones reported for $\mathrm{CAU}-13,{ }^{25}$ which contains cyclohexanedicarboxylate ions and also exhibits the MIL-53-type structure. Hence, a ligand replacement strategy was applied to the structure of CAU-13 while the space group was converted from $P \overline{1}$ to $P 1$. This structural model without water molecules was then geometry optimized at the force field level by imposing the cell parameters to the indexed values. The resulting structural model could not be refined by Rietveld methods due to a lower crystallinity of this form compared to the anhydrous solid. Hence, this structural model was completed by including one water molecule per formula unit as determined from TGA and water sorption experiments and subsequently optimised by DFT calculations, retaining the indexed cell parameters and taking also the hydrogen atoms into account in order to get a more reliable model. Such an approach has been proven highly valuable for the structure elucidation of complex and weakly ordered materials. ${ }^{22,39}$ The final optimised model was converted to conventional cell parameter settings (Table 1) and led to a simulated PXRD pattern in reasonable agreement with that observed (Fig. S1†). However, the intensities especially at low $2 \theta$ values are much lower than expected for a highly crystalline structure. We attribute this to severe disorder of the $\mathrm{H}_{2} \mathrm{O}$ guest molecules as well as to the relatively easy conformational changes of the aliphatic linker molecules induced by small rotational movements which require small activation barriers to be overcome. Accounting for this by using the spherical harmonics corrections for an initial fit without any structural refinement gives a reasonable agreement of the calculated and simulated PXRD pattern (see ESI $\dagger$ ). The spherical harmonics correction is usually applied for modelling of deviating intensities in case of strong textural effects, however, in this case we attribute these deviations to the pronounced disorder in Al-MIL-53-ADP-lp.

\section{Structure description}

The framework structures of Al-MIL-53-ADP-np and Al-MIL-53ADP-lp are based on the connection of infinite chains of trans corner sharing $\mathrm{AlO}_{6}$-polyhedra via adipate anions (Fig. 2). The flexible adipate molecules adopt conformations that lead to an uncommon "Z"-shape of the one-dimensional pores. Taking the $\mathrm{H}$-atoms of the linker molecules into account, which were not localised during the Rietveld refinement, Al-MIL-53-ADPnp must be considered as a dense structure. The packing of these channels is substantially different compared to the ones observed in most other MIL-53-type structures. ${ }^{13,19}$

For compounds based on aromatic linker molecules, the channels exhibit rectangular shape and opposite channel walls that are strictly parallel to each other. The shape of the channels in Al-MIL-53-ADP-np rather resembles a " $\mathrm{Z}$ " and thus the 

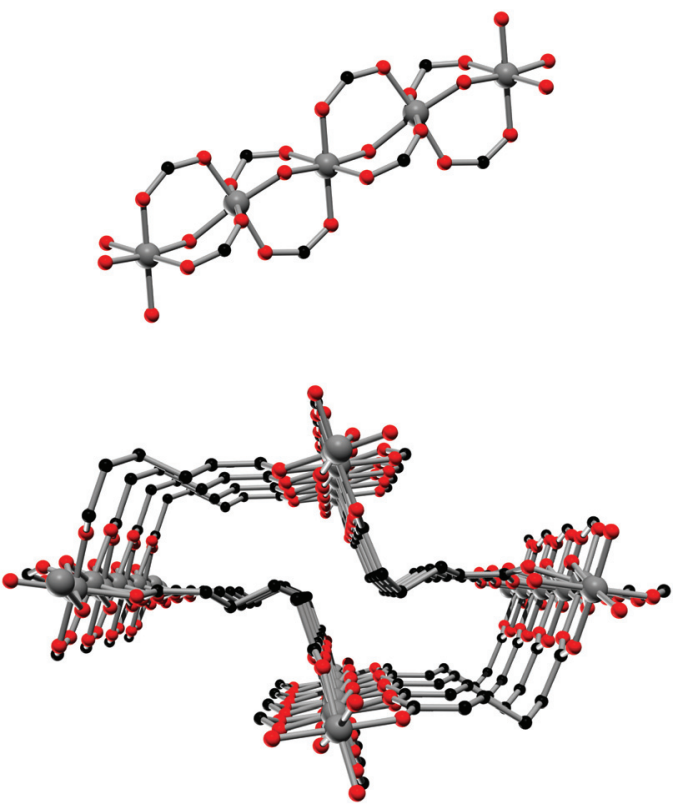

Fig. 2 Top: The infinite chain of trans corner sharing $\mathrm{AlO}_{6}$-polyhedra. Bottom: one channel in the structure of Al-MIL-53-ADP-np as seen along the $c$-axis, showing also the conformation of the adipate linker molecules. Aluminium atoms in grey, oxygen atoms in red and carbon atoms in black.

observed packing does not show parallel opposite channel walls (Fig. 3).

The crystal structure of Al-MIL-53-ADP-Ip does not show any change in connectivity but represents a hydrated analogue of the narrow pore form. Due to the insertion of water molecules the channels open up to a size suitable to accommodate water molecules. Thus the channel diameter as determined by pore size distribution analysis carried out on the structural model is ca. $3.2 \AA$ (Fig. 4 and S3†). The shape of the channels rather resembles a kinked variant of the normal rhombic form.

The hydrated structure reveals that the water molecules are arranged in such a way to form hydrogen bonds with both the $\mu_{2}-(\mathrm{OH})$ groups and one oxygen atom of one carboxylate group

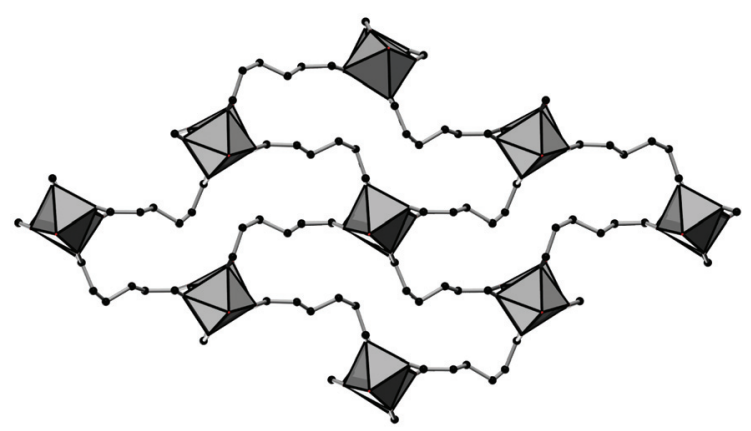

Fig. 3 The structure of Al-MIL-53-ADP-np as seen along the $c$ axis, showing the packing of the "Z"-shaped channels. AlO polyhedra in grey and carbon atoms in black.

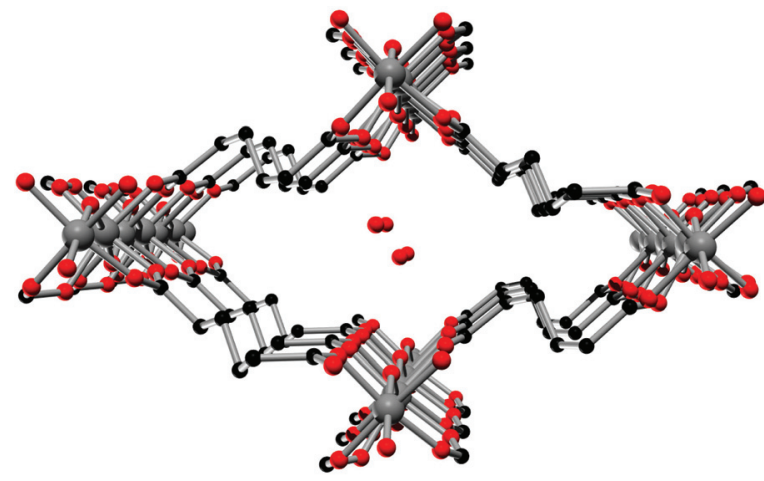

Fig. 4 One channel in the structure of Al-MIL-53-ADP-lp as seen along the $a$ axis. Hydrogen atoms are omitted for clarity. Aluminium atoms in grey, oxygen atoms in red and carbon atoms in black.

with characteristic distances between two water/host oxygen atoms ranging from 2.88 to $3.04 \AA$. In addition to this, the confined water molecules form a relatively strong hydrogen bond network with corresponding Ow_Ow distances (2.92 ̊). This spatial distribution and the relevant interactions are very similar to that previously pointed in the MIL-53 series. ${ }^{22,40}$ Remarkably, the adsorption of water induces a rotation of the AlO-polyhedra chains and a framework expansion of $\approx 10 \%$ ( $v s$. $3-4 \%$ and $33 \%$ for Al-MIL-53-FUM ${ }^{22}$ and Al-MIL-53-BDC ${ }^{13}$ respectively) while the length of the linker molecules is decreased due their conformational changes. The distances between carboxylate groups in the independent linker molecules in Al-MIL-53-ADP-np are 5.79(2) and 5.90(2) A while they are 5.43 and $5.7 \AA$ in the hydrated form Al-MIL-53-ADP-lp. This "shortening" of the linker molecules could also allow for an easier rotation around the $\mathrm{C}-\mathrm{C}$ bonds and therefore might be the reason for the observed disordering in the crystal structure. A comparison with the well known highly crystalline layered compound zinc adipate $^{41}$ pronounces the conformationally compressed character of the linker molecules. Zinc adipate incorporates adipate ions in their longest possible conformation and therefore the average distance between carboxylate groups amounts to 6.432(4) $\mathrm{\text {(Fig.5) }}$.

This change in conformation also seems to be the dominant mechanism controlling the breathing behaviour. In the aromatic parent compound Al-MIL- $53^{13}$ the knee-cap mechanism results in profound changes in the angle between adjacently coordinated carboxylate groups. These values amount to $100^{\circ}$ and $128^{\circ}$ in the large pore and the narrow pore forms of the Al-MIL53-BDC solids, respectively. Here the scenario is different: for the hydrated Al-MIL-53-ADP-lp, the angles between crystallographically independent groups are 97 and $103^{\circ}$ and upon dehydration to the narrow pore form they only slightly change to 97 and $107^{\circ}$ (Fig. S4 $\dagger$ ).

It is worth mentioning that we also tried to intercalate several other solvent molecules like ethanol, acetone, toluene or dimethylformamide by dispersion of the dried MOF at elevated temperature, but all attempts proved unsuccessful. 

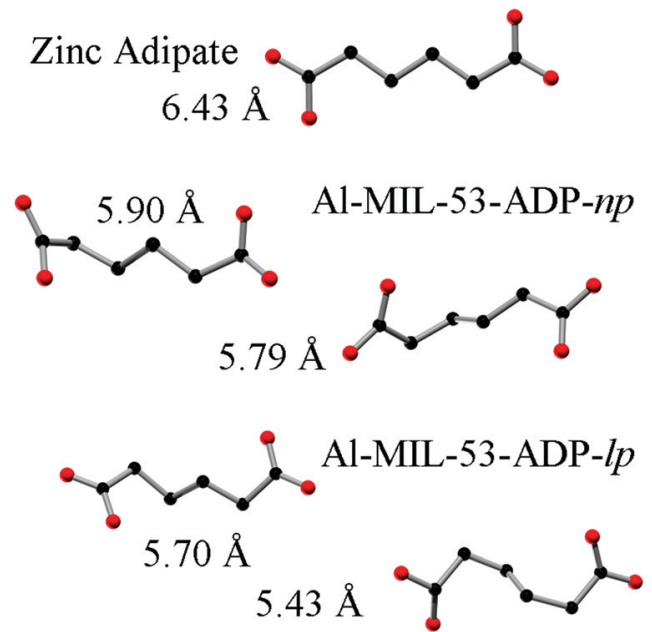

Fig. 5 Conformation and lengths (carboxylate to carboxylate) of the adipate molecules in Al-MIL-53-ADP and for comparison also in zinc adipate. $^{41}$

\section{Properties of Al-MIL-53-ADP}

The IR-spectrum of Al-MIL-53-ADP-lp is shown in Fig. 6. It is particularly relevant that no signals of residual dimethylformamide molecules or unreacted adipic acid are visible. The most prominent signals are the peaks at 1570 and $1460 \mathrm{~cm}^{-1}$ which can be attributed to the asymmetric carboxylate vibration and the deformation vibration of the $\mathrm{CH}_{2}$-groups, respectively. ${ }^{42}$ Between 2960 and $2840 \mathrm{~cm}^{-1}$ several signals can be detected which belong to $\mathrm{C}-\mathrm{H}$ stretching vibrations of the aliphatic linker molecule backbone. The intensity of the broad band around $3500 \mathrm{~cm}^{-1}$ varies, depending on the degree of hydration which can vary during the preparation of the sample.

The thermogravimetric curve (Fig. 7) was measured for a sample prepared directly after filtration from an aqueous dispersion and shows two distinct weight losses. The first step is due to the dehydration of the structure (10 wt\%) while the second step of $63.4 \%$ above $360{ }^{\circ} \mathrm{C}$ is attributed to the

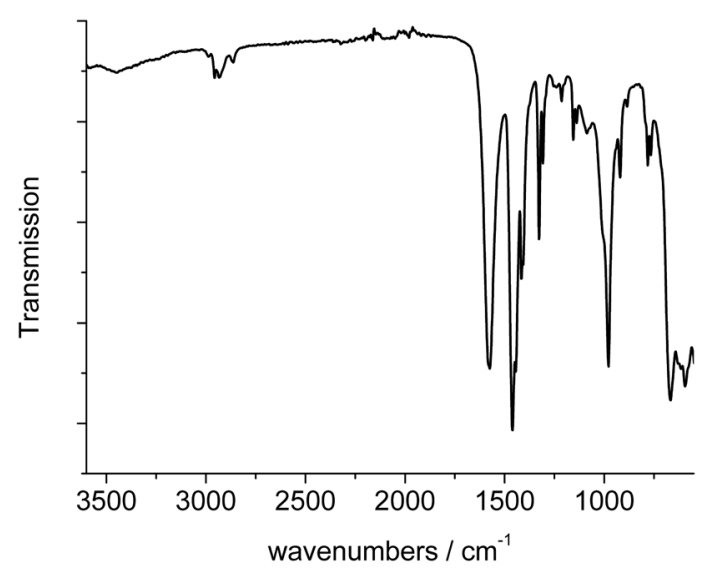

Fig. 6 IR-spectrum of Al-MIL-53-ADP-lp.

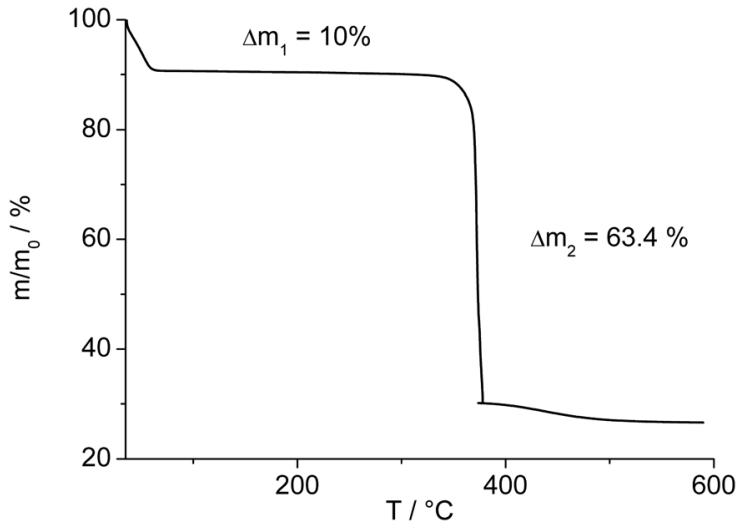

Fig. 7 Thermogravimetric curve for Al-MIL-53-ADP-lp.

decomposition of the framework. The first weight loss of $10 \mathrm{wt} \%$ is slightly larger than the expected value ( $9 \mathrm{wt} \%$ ) while the second step $(63.4 \%)$ is slightly smaller than the expected loss $(66.5 \%)$ based on the deduced composition $\left[\mathrm{Al}(\mathrm{OH})\left(\mathrm{O}_{2} \mathrm{C}-\right.\right.$ $\left.\left.\mathrm{C}_{4} \mathrm{H}_{8}-\mathrm{CO}_{2}\right)\right] \cdot \mathrm{H}_{2} \mathrm{O}$. Taking into account that there are still sulphur containing impurities present, both values are in reasonable agreement with the expected ones.

In order to investigate the sorption properties of Al-MIL-53ADP, several sorption isotherms were measured. However, no uptake was observed for $\mathrm{N}_{2}$ at $-196{ }^{\circ} \mathrm{C}$ or for $\mathrm{CO}_{2}$ at $25{ }^{\circ} \mathrm{C}$, regardless of activation conditions $\left(0.1 \mathrm{mbar}\right.$, between $100{ }^{\circ} \mathrm{C}$ and $200^{\circ} \mathrm{C}$ ). Only for water vapour we observed a considerable adsorption. The isotherm is shown in Fig. 8 and exhibits a strong hysteresis loop. By measuring PXRD patterns depending on relative humidity we were able to identify the respective framework conformation during the sorption process (Fig. 8).

The adsorption of water at $25^{\circ} \mathrm{C}$ starts at a relative humidity of $\approx 55 \%$ and proceeds in one step. The adsorbed amount of $1.1 \mathrm{H}_{2} \mathrm{O}$ per aluminium atom is in good agreement with the expected amount of 1 molecule. Compared to the adsorption step at $\approx 55 \%$ relative humidity, the desorption starts at a much lower value of $\approx 25 \%$. Such hysteretic water sorption isotherms are often observed in breathing MOFs, for example for Al-MIL-53-(OH $)_{2}{ }^{17}$ or Al-MIL-53-(1,4-NDC). ${ }^{43}$ The PXRD data indicate a rather slow equilibration during the uptake and release of $\mathrm{H}_{2} \mathrm{O}$ molecules. Diffractograms measured at $60 \%$ relative humidity during uptake show in general both forms, Al-MIL-53-ADP-np and Al-MIL-53-ADP-lp.

Nearly all of the dry form is converted after 20 minutes of equilibration at $70 \%$ relative humidity. The same mixture of framework conformers is observed for the desorption curve at $20 \%$ relative humidity. Moreover, even after extended equilibration under very moist (relative humidity $>70 \%$ ) or very dry (relative humidity $<20 \%$ ) conditions, there are still traces of the respective counterpart conformation present. A possible explanation could be that the diffusion into and out of the very narrow pores in Al-MIL-53-ADP is very slow and thus impedes fast equilibration times below 30 minutes. In addition the MOF crystals show a strong tendency for intergrowth, indi- 

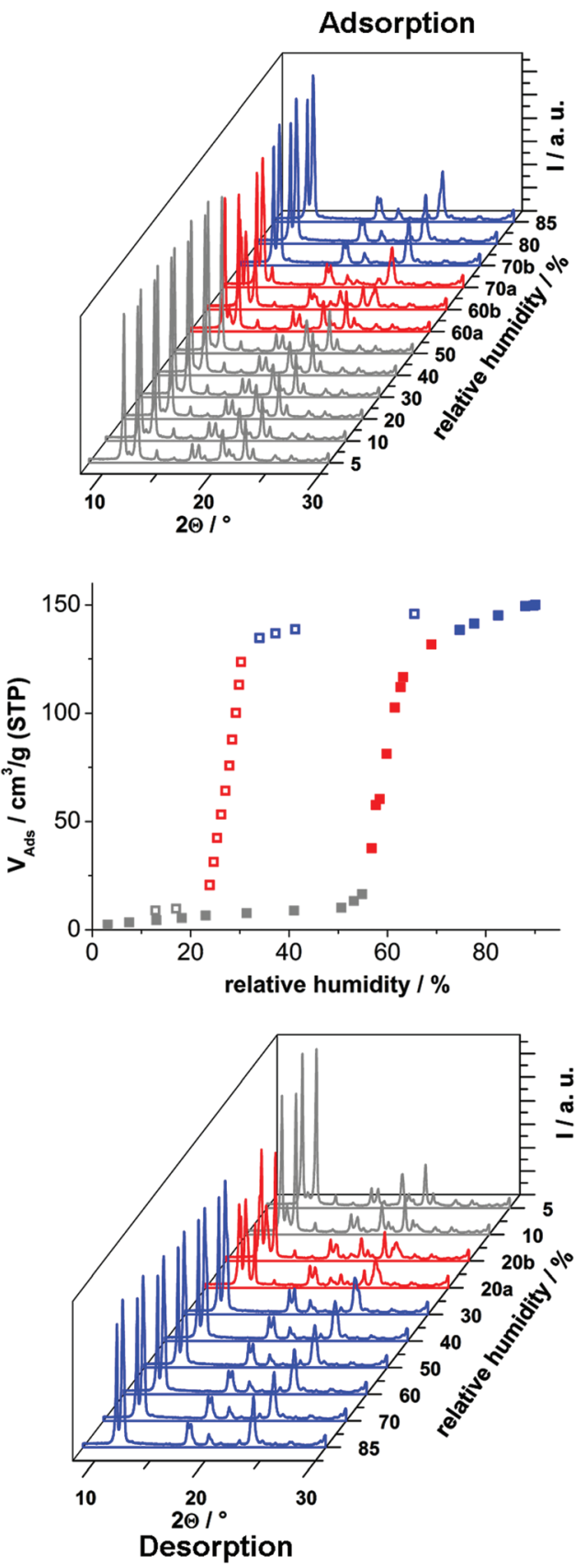

Fig. $8 \quad \mathrm{H}_{2} \mathrm{O}$ vapour isotherm for Al-MIL-53-ADP and the PXRD patterns depending on relative humidity, measured at $298 \mathrm{~K}$. The colours indicate the respective framework conformation present. Blue indicates the hydrated Al-MIL-53-ADP-lp, grey indicates the dehydrated Al-MIL-53ADP-np and red indicates a mixture of both conformations. Patterns for $60 \%$ and $70 \%$ r. h. during adsorption and $20 \%$ r. h. during desorption are plotted directly after the humidity value is reached (a) and after 20-45 minutes equilibration (b).

cated by the formation of a thick layer of product at the glass reactor walls during the synthesis. This might also slow down the interparticle diffusion between intergrown crystals and thus delay equilibration.

\section{Solid-state NMR}

The ${ }^{1} \mathrm{H}$ NMR spectra of both Al-MIL-53-ADP forms (Fig. 9) exhibit a broad resonance around $1.9 \mathrm{ppm}$ which consists of overlapping peaks of the $\mathrm{CH}_{2}$ and the Al-OH groups. This is confirmed by the first principle DFT calculations performed on the crystal structure of Al-MIL-53-ADP-np which evidence that the chemical isotropic shifts are very similar for both $\mathrm{H}$ species $\left(\delta_{\text {iso }}\left(\mathrm{H}_{(\mathrm{Al}-\mathrm{OH})}=2.0 \mathrm{ppm} v\right.\right.$ s. $\left.\delta_{\text {iso }}\left(\mathrm{H}_{\mathrm{CH}_{2}}\right)=1.8 \mathrm{ppm}\right)$ see Table S2 $\dagger$ ) Additionally, Al-MIL-53-ADP-lp exhibits two sharper resonances at 2.7 and $3.0 \mathrm{ppm}$ which were attributed to the two crystallographically inequivalent water molecules observed for this structure as also qualitatively shown by first principle calculations (see Table S2 $\uparrow$ ).

The ${ }^{13} \mathrm{C}$ spectra (Fig. 10) show three well-separated peak regions characteristic of the three different carbon types in the structures. While the carboxyl units are observed between 179 and $182 \mathrm{ppm}$, the outer and inner pairs of $\mathrm{CH}_{2}$ groups resonate in the ranges $37.0-38.2 \mathrm{ppm}$ and $23.7-25.8 \mathrm{ppm}$, respectively. In the case of Al-MIL-53-ADP-np, six resonances - each two for the inner and outer $\mathrm{CH}_{2}$ groups $(23.7 / 25.8 \mathrm{ppm}$ and $37.1 / 38.1 \mathrm{ppm})$ as well as for the $\mathrm{CO}_{2}$ units (179.7/179.8 ppm)) - were observed. These observations are again in very good agreement with our DFT predicted ${ }^{13} \mathrm{C}$ NMR parameters for both $\mathrm{CH}_{2}$ groups (22.5/25.2 ppm and 36.4/37.2 ppm) and $\mathrm{CO}_{2}$ units $(183.4 \mathrm{ppm})$, this accounts for half of the possible resonances with respect to the structural model. Since the two adipate ions in the asymmetric unit are almost inversion symmetric we expect that the intramolecular splitting between resonances of similar chemical units of the same adipate molecule could not be resolved.

Due to the pronounced dynamical disorder of the $\mathrm{CH}_{2}$ units of adipate molecules and the water molecules the shift differences between similar inner and outer $\mathrm{CH}_{2}$ units, respectively, are averaged for Al-MIL-53-ADP-lp. This leads to only two resonances at 24.9 and $37.6 \mathrm{ppm}$ in this region. In contrast, for the carboxylic groups of Al-MIL-53-ADP-lp two well resolved resonances at 180.8 and 181.4 ppm with a splitting of $0.6 \mathrm{ppm}$ are visible. These experimental data are consistent with the theoretical findings reported in Table S2. $\dagger$

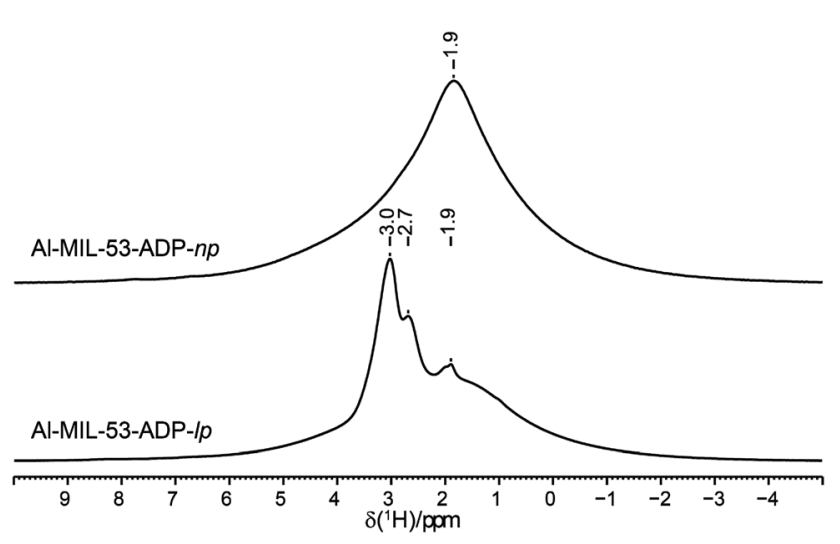

Fig. $9{ }^{1} \mathrm{H}$ MAS NMR spectra of Al-MIL-53-ADP. 


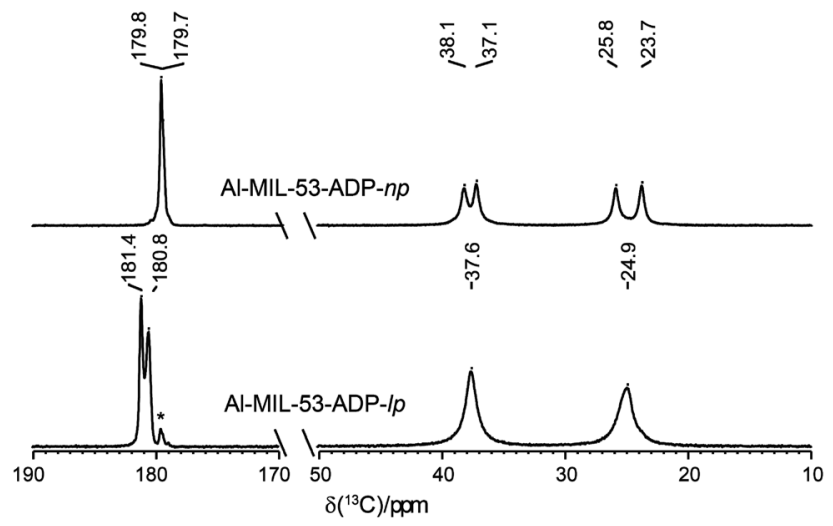

Fig. $10{ }^{13} \mathrm{C}$ CP MAS NMR spectra of Al-MIL-53-ADP. The resonances marked with an asterisk represent a small impurity of the $n p$ form in the Ip phase.

The ${ }^{27} \mathrm{Al}$ NMR spectra of both phases are displayed in Fig. 11 along with their simulated spectra including chemical shift and second order quadrupolar interactions (Table 2). For both the $\mathrm{np}$ and the lp forms two individual resonances were observed which is in line with the structure solutions of the PXRD data. All resonances exhibit isotropic chemical shifts close to zero reflecting the octahedral coordination of the $\mathrm{Al}^{3+}$ ions. The significantly different quadrupolar coupling constants $C_{\mathrm{Q}}$ and asymmetry parameters $\eta$ for the np phase demonstrate that the local environment of both $\mathrm{Al}$ octahedra

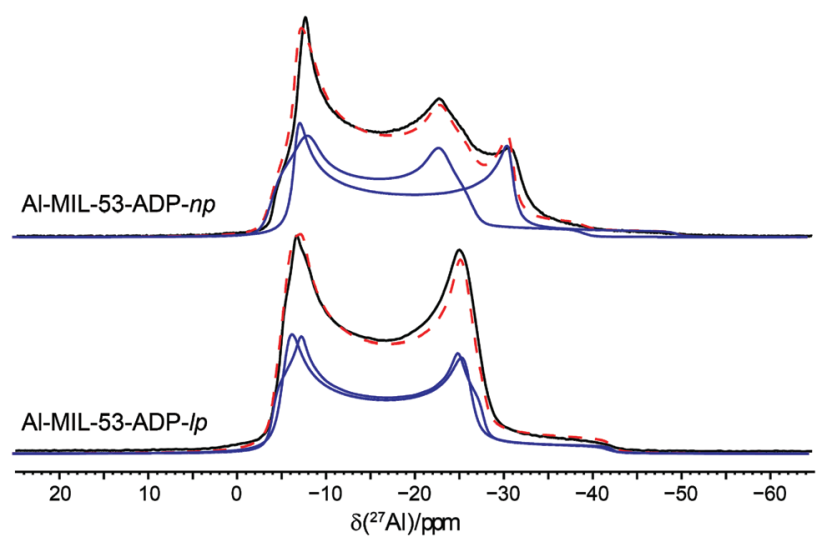

Fig. $11{ }^{27} \mathrm{Al}$ MAS NMR spectra of Al-MIL-53-ADP along with their respective fitted spectra (- individual resonances, -- sum of all resonances).

Table 2 Relevant refinement parameters for the ${ }^{27} \mathrm{Al}$ MAS spectra of Al-MIL-53-ADP

\begin{tabular}{lll}
\hline & {$\left[\mathrm{Al}(\mathrm{OH})\left(\mathrm{O}_{2} \mathrm{C}-\mathrm{C}_{4} \mathrm{H}_{8}-\mathrm{CO}_{2}\right)\right]$} & {$\left[\mathrm{Al}(\mathrm{OH})\left(\mathrm{O}_{2} \mathrm{C}-\mathrm{C}_{4} \mathrm{H}_{8}-\mathrm{CO}_{2}\right)\right] \cdot \mathrm{H}_{2} \mathrm{O}$} \\
\hline$\delta_{\text {iso }} / \mathrm{ppm}$ & $0.2 /-0.5$ & $0.2 / 0.3$ \\
$C_{\mathrm{Q}} / \mathrm{MHz}$ & $9.06 / 7.96$ & $8.32 / 8.37$ \\
$\eta$ & $0.0 / 0.19$ & $0.0 / 0.13$
\end{tabular}

differs markedly (Table 2). The $C_{\mathrm{Q}}(9.06 \mathrm{MHz}, 7.96 \mathrm{MHz})$ obtained for the anhydrous form are consistent with the experimental findings previously reported for the dry AlMIL-53-BDC $\left(C_{\mathrm{Q}}=8.3 \mathrm{MHz}\right)$ and Al-MIL-53-FUM (8.7 $\left.\mathrm{MHz}\right)$ materials. ${ }^{22}$ And they also match with the corresponding firstprinciple calculated NMR parameters $(8.60 \mathrm{MHz}, 7.90 \mathrm{MHz}){ }^{22}$ The quadrupolar interactions of the Al nuclei in the lp phase turn out to be very similar (8.32 and $8.37 \mathrm{MHz}$ see Table 2) and could almost be assimilated into one single resonance. This is in contrast to the first-principles calculations where two types of $\mathrm{Al}^{3+}$, with $C_{\mathrm{Q}}$ values of $8.3 \mathrm{MHz}$ and $12.5 \mathrm{MHz}$ respectively have been found (see Table S2 $\dagger$ ). This deviation probably results from a dynamical disorder, which was experimentally observed for this phase.

Overall, the NMR experimental findings are in agreement with the corresponding first principles calculated parameters determined from the resolved crystal structures and support the reliability of the proposed structural models.

\section{Conclusions}

Herein we reported the synthesis and detailed characterisation of the first analogue of Al-MIL-53 based on a single chain saturated aliphatic linker molecule. This opens also the opportunity to study other aliphatic carboxylic acids like succinic acid $\left(\mathrm{C}_{4}\right.$ chain) or suberic acid $\left(\mathrm{C}_{8}\right.$ chain), which might also form breathing frameworks. The combination of complementary PXRD, solid state NMR and modelling tools was shown to be necessary to elucidate the crystal structures of the anhydrous and hydrated MIL-53-ADP which show pronounced disorder phenomena. Regarding the sorption properties it is especially of interest if functionalisation or extension of the linker molecules would be possible, which might result in similarly selective sorption behaviour towards other guest molecules than water.

\section{Acknowledgements}

The research leading to these results has received funding from the European Community's Seventh Framework Programme Macademia (FP7/2007-20013) under grant agreement no 228862 ". G. M. thanks Institut Universitaire de France for its support. This work has also been supported by the DFG (SE 1417/7-1).

\section{Notes and references}

1 M. P. Suh, H. J. Park, T. K. Prasad and D. Lim, Chem. Rev., 2012, 112, 782.

2 J. Liu, P. K. Thallapally, B. P. McGrail, D. R. Brown and J. Liu, Chem. Soc. Rev., 2012, 41, 2308.

3 F. Vermoortele, M. Maes, P. Modhadam, M. Lennox, F. Ragon, M. Boulhout, S. Biswas, K. Laurier, I. Beurroies, R. Denoyel, M. Roeffaers, N. Stock, T. Düren, C. Serre and D. De Vos, J. Am. Chem. Soc., 2011, 133, 18529. 
4 P. Valvekens, F. Vermoortele and D. De Vos, Catal. Sci. Technol., 2013, 13, 1435.

5 O. Shekhah, J. Liu, R. A. Fischer and C. Wöll, Chem. Soc. Rev., 2011, 40, 1081.

6 G. Ferey, Z. Anorg. Allg. Chem., 2012, 638, 1897.

7 A. Schneeman, V. Bon, I. Schwedler, I. Senkovska, S. Kaskel and R. A. Fischer, Chem. Soc. Rev., 2014, 43, 6062.

8 C. Serre, C. Mellot-Draznieks, S. Surble, N. Audebrand, Y. Filinchuk and G. Ferey, Science, 2007, 315, 1828.

9 J. P. S. Mowat, S. R. Miller, A. M. Z. Slawin, V. R. Seymour, S. E. Ashbrook and P. A. Wright, Microporous Mesoporous Mater., 2011, 142, 322.

10 K. Barthelet, J. Marrot, D. Riou and G. Ferey, Angew. Chem., Int. Ed., 2002, 114, 291.

11 C. Serre, F. Millange, C. Thouvenot, M. Noguès, G. Marsolier, D. Louër and G. Férey, J. Am. Chem. Soc., 2002, 124, 13519.

12 T. R. Whitfield, X. Wang, L. Liu and A. J. Jacobson, Solid State Sci., 2005, 7, 1096.

13 T. Loiseau, C. Serre, C. Huguenard, G. Fink, F. Taulelle, M. Henry, T. Bataille and G. Ferey, Chem. - Eur. J., 2004, 10, 1373.

14 C. Volkringer, T. Loiseau, N. Guillou, G. Ferey, E. Elkaim and A. Vimont, Dalton Trans., 2009, 2241.

15 V. Anokhina, M. Vougo-Zanda, X. Wang and A. J. Jacobson, J. Am. Chem. Soc., 2005, 127, 15000-15001.

16 T. Devic, P. Horcajada, C. Serre, F. Salles, G. Maurin, B. Moulin, D. Heurtaux, G. Clet, A. Vimont, J.-M. Greneche, B. Le Ouay, F. Moreau, E. Magnier, Y. Filinchuk, J. Marrot, J.-C. Lavalley, M. Daturi and G. Ferey, J. Am. Chem. Soc., 2010, 132, 1127.

17 S. Biswas, T. Ahnfeldt and N. Stock, Inorg. Chem., 2011, 50, 9518.

18 A. Centrone, T. Harada, S. Speakman and T. A. Hatton, Small, 2010, 6, 1598.

19 I. Senkovska, F. Hoffmann, M. Fröba, J. Getzschmann, W. Böhlmann and S. Kaskel, Microporous Mesoporous Mater., 2009, 122, 93.

20 T. Loiseau, C. Mellot-Draznieks, H. Muguerra, G. Ferey, M. Haouas and F. Taulelle, C. R. Chim., 2005, 8, 765.

21 Y. Liu, K. Leus, M. Grzywa, D. Weinberger, K. Strubbe, H. Vrielinck, R. Van Deun, D. Volkmer, V. Van Speybroeck and P. Van Ver Voort, Eur. J. Inorg. Chem., 2012, 16, 2819.

22 E. Alvarez, N. Guillou, C. Martineau, B. Bueken, B. Van de Voorde, C. Le Guillouzer, P. Fabry, F. Nouar, F. Taulelle, D. de Vos, J. Chang, K. H. Cho, N. Ramsahye, T. Devic, M. Daturi, G. Maurin and C. Serre, Angew. Chem., Int. Ed., 2015, 54, 3664.

23 L. Wang, T. Song, C. Li, J. Xia, S. Wang, L. Wang and J. Xu, J. Solid State Chem., 2012, 190, 208.

24 I. H. Kim, X. Wang and A. J. Jacobson, Solid State Sci., 2010, 12, 76.

25 F. Niekiel, M. Ackermann, P. Guerrier, A. Rothkirch and N. Stock, Inorg. Chem., 2013, 52, 8699.

26 F. Niekiel, J. Lannoeye, H. Reinsch, A. Munn, A. Heerwig, I. Zizak, S. Kaskel, R. Walton, D. de Vos, P. Llewellyn,
A. Lieb, G. Maurin and N. Stock, Inorg. Chem., 2014, 53, 4610.

27 H. Reinsch and D. De Vos, Microporous Mesoporous Mater., 2014, 200, 311.

28 Topas Academics 4.2, Coelho Software, 2007.

29 Materials Studio Version 5.0, Accelrys Inc., San Diego, CA, 2009.

30 (a) J. VandeVondele, M. Krack, F. Mohamed, M. Parrinello, T. Chassaing and J. Hutter, Comput. Phys. Commun., 2005, 167, 103; (b) J. VandeVondele and J. Hutter, J. Chem. Phys., 2003, 118, 4365; (c) G. Lippert, J. Hutte and M. Parrinello, Theor. Chem. Acc., 1999, 103, 124; (d) B. G. Lippert and J. H. M. Parrinello, Mol. Phys., 1997, 92, 477; (e) J. VandeVondele and J. Hutter, J. Chem. Phys., 2007, 127, 114105; $(f)$ S. Goedecker, M. Teter and J. Hutter, Phys. Rev. B: Condens. Matter, 1996, 54, 1703; $(g)$ S. Grimme, J. Antony, S. Ehrlich and H. Krieg, J. Chem. Phys., 2010, 132, 154104.

31 M. D. Segall, P. L. D. Lindan, M. J. Probert, C. J. Pickard, P. J. Hasnip, S. J. Clark and M. C. J. Payne, J. Phys.: Condens. Matter, 2002, 14, 2717.

32 S. J. Clark, M. D. Segall, C. J. Pickard, P. J. Hasnip, M. J. Probert, K. Refson and M. C. Payne, Z. Kristallogr., 2005, 220, 567.

33 J. P. Perdew, K. Burke and M. Ernzerhof, Phys. Rev. Lett., 1996, 77, 3865.

34 J. R. Yates, C. J. Pickard and F. Mauri, Phys. Rev. B: Condens. Matter, 2007, 76, 024401.

35 M. Profeta, F. Mauri and C. J. Pickard, J. Am. Chem. Soc., 2003, 125, 541.

36 C. J. Pickard and F. Mauri, Phys. Rev. B: Condens. Matter, 2001, 63, 245101.

37 M. Sanselme, J.-M. Grenèche, M. Riou-Cavelleca and G. Férey, Solid State Sci., 2004, 6, 853.

38 W. Kraus and G. Nolze, PowderCell 2.4, 2000.

39 (a) B. Meredig and C. Wolverton, Nat. Mater., 2013, 12, 123; (b) A. Cadiau, J. S. Lee, D. D. Borges, P. Fabry, T. Devic, M. T. Wharmby, C. Martineau, D. Foucher, F. Taulelle, C. H. Jun, Y. K. Hwang, N. Stock, M. F. De Lange, F. Kapteijn, J. Gascon, G. Maurin, J. S. Chang and C. Serre, Adv. Mater., 2015, 27, 4775; (c) C. Martineau, Solid State Nucl. Magn. Reson., 2014, 63-64, 1; (d) S. Devautour-Vinot, G. Maurin, C. Serre, P. Horcajada, D. Cunha, V. Guillerm, E. De Souza Costa, F. Taulelle and C. Martineau, Chem. Mater., 2012, 24, 2168.

40 S. Bourrelly, B. Moulin, A. Rivera, G. Maurin, S. DevautourVinot, C. Serre, T. Devic, P. Horcajada, A. Vimont, G. Clet, M. Daturi, J.-C. Lavalley, S. Loera-Serna, R. Denoyel, P. L. Llewellyn and G. Férey, J. Am. Chem. Soc., 2010, 132, 9488.

41 S. Klaus, M. W. Lehenmeier, E. Herdtweck, P. Deglmann, A. K. Ott and B. Rieger, J. Am. Chem. Soc., 2011, 133, 13151.

42 G. Socrate, Infrared and Raman Characteristic Group Frequencies: Tables and Charts, John Wiley \& Sons, 2004.

43 A. Comotti, S. Bracco, P. Sozzani, S. Horike, R. Matsuda, J. Chen, M. Takata, Y. Kubota and S. Kitagawa, J. Am. Chem. Soc., 2008, 130, 13664. 